\title{
Ciclo Diurno do Conforto Térmico Humano em Maceió-AL
}

\author{
Helen da Silva Mendonça ${ }^{1}$ (D), Fabrício Daniel dos Santos Silva ${ }^{1}$ (D), \\ Rodrigo Lins da Rocha Júnior ${ }^{1}$ (D), Djane Fonseca da Silva ${ }^{1}$ (D), Maria Luciene Dias de Melo ${ }^{2}$ (D), \\ Rafaela Lisboa Costa ${ }^{1}$ (D), Heliofábio Barros Gomes ${ }^{1}$ (D), Vicente de Paulo Rodrigues da Silva ${ }^{2}$ (D), \\ Bruce Kelly da Nóbrega Silva ${ }^{3}$ (D) \\ ${ }^{1}$ Instituto de Ciências Atmosféricas, Universidade Federal de Alagoas, Maceió, AL, Brasil. \\ ${ }^{2}$ Unidade Acadêmica de Ciências Atmosféricas, Universidade Federal de Campina Grande, \\ Campina Grande, PB, Brasil. \\ ${ }^{3}$ Programa de Pós Graduação em Ciências Climáticas, Universidade Federal do Rio Grande do \\ Norte, Natal, RN, Brasil.
}

Recebido em: 30 de Junho de 2020 - Aceito em: 30 de Julho de 2020

\begin{abstract}
Resumo
Alterações no uso e ocupação do solo das cidades tem consequências diretas no campo térmico urbano, cujas características físicas e microclimáticas tornam-se atrativos à convivência humana. Esta pesquisa teve como objetivo analisar a variação de um índice biometeorológico e estudar quantitativamente o ciclo diurno do conforto térmico humano em Maceió-AL, por meio de dados horários disponibilizados pela estação meteorológica automática do Instituto Nacional de Meteorologia (INMET) entre os anos de 2004 a 2015. Em média, observa-se sensação de conforto das 00 às 09 horas UTC; das 11 às 20 UTC prevalece a sensação de desconforto térmico pelo calor. A partir das 21 UTC o desconforto devido ao calor vai apresentando uma diminuição e o conforto começa a aumentar, prevalecendo essa sensação, não sendo identificados casos de desconforto ou estresse devido ao frio. É comum, a depender da época do ano, ocorrência de horas de estresse pelo calor entre 10 a 19 UTC, com maior frequência das 15 às 17 UTC. Apesar de constatados desconforto e estresse por calor, predomina na maior parte das horas do dia condições de conforto, não sendo observados em todo o período de estudo nenhum caso de desconforto por frio.
\end{abstract}

Palavras-chave: temperatura do ar, temperatura do ponto de orvalho, índice de desconforto de Kawamura.

\section{Diurnal Cycle of Human Thermal Comfort in Maceió-AL}

\begin{abstract}
Changes in land use and occupation in cities have direct consequences in the urban thermal field, whose physical and microclimate characteristics become attractive to human coexistence. This research aimed to analyze the variation of a biometeorological index and to quantitatively study the diurnal cycle of human thermal comfort in Maceió-AL, using hourly data provided by the automatic meteorological station of the National Institute of Meteorology (INMET) between the years 2004 to 2015. On average, there is a feeling of comfort from 00 to 09 UTC; from 11 to 20 UTC the sensation of thermal discomfort by heat prevails. After 21 UTC, the discomfort due to heat decreases and comfort begins to increase, with this feeling prevailing, with no cases of discomfort or stress due to the cold being identified. It is common, depending on the time of year, for hours of heat stress between 10 to 19 UTC, more frequently from 15 to 17 UTC. Despite discomfort and heat stress, comfort conditions prevail in most hours of the day, with no case of discomfort due to cold being observed throughout the study period.
\end{abstract}

Keywords: air temperature, dew point temperature, Kawamura discomfort index.

Autor de correspondência: Fabrício Daniel dos Santos Silva, fabricio.santos@icat.ufal.br. 


\section{Introdução}

O processo de urbanização vem se acelerando em muitas cidades, aumentando a área física construída com substituição intensiva das áreas verdes, levando a um crescente interesse dessa implicação na saúde humana (Moore et al., 2003; Wang et al., 2012; Azevedo et al., 2015; Li et al., 2017). Costa et al. (2020) mostraram que a região nordeste do Brasil apresenta tendência de aumento positivo de índices de extremos climáticos de temperaturas máximas e mínimas na maior parte dos municípios estudados, incluindo-se todas as capitais de Estado desta região. O aquecimento pode variar por região, e pode se dar por causa de fatores naturais ou fatores antropogênicos como as ilhas de calor em grandes cidades, ou devido à combinação dos dois (Freitas et al., 2006; Qaid et al., 2016).

As características ambientais de espaços públicos urbanos, por sua vez, incluem aspectos físicos e microclimáticos que contribuem para torná-los mais ou menos atrativos à convivência humana. Esses espaços ganham significados de acordo com o contexto urbano e as características locais, que juntos irão determinar seus usos, seja de passagem ou de permanência. Dessa forma, o entendimento das características do espaço urbano influência de forma positiva ou negativa os microclimas e o conforto térmico dos pedestres, tornando-se imprescindíveis para subsidiar o planejamento e o projeto do espaço público (Labaki et al., 2012).

Zhao et al. (2018) estudaram dados de variáveis meteorológicas e internações hospitalares de 1814 cidades do Brasil entre 2000 e 2015, compreendendo $78 \%$ da população brasileira, e concluíram que a exposição as variações de temperatura contribuem com aproximadamente $4 \%$ de todas as internações do País, com maior taxa de internações em crianças com idade inferior a 5 anos, seguidos de idosos e por fim, pessoas na faixa etária de 10 a 49 anos.

Bracarense et al. (2018) define a importância dos estudos de conforto térmico a partir da presença de três fatores como: a satisfação do homem ou seu bem-estar permitindo se sentir termicamente confortável; a performance humana, onde os estudos mostram uma clara tendência de que o desconforto causado por calor ou frio reduz o desempenho nas atividades intelectuais, manuais e perceptivas; e a conservação de energia, pois conhecendose as condições e características referentes ao conforto térmico dos ocupantes do ambiente evitam-se desperdícios com calefação e refrigeração.

Quando as trocas de calor entre o corpo humano e o ambiente ocorrem sem maior esforço, a sensação do indivíduo é de conforto térmico e sua capacidade de trabalho é máxima. Se as condições térmicas ambientais causam sensação de frio ou de calor, é porque nosso organismo está, nesse caso, perdendo mais ou menos calor que o necessário para a manutenção da homeotermia, à qual passa a ser conseguida com um esforço adicional que representa sobrecarga, com queda do rendimento no trabalho, até o limite. Sob condições de rigor excepcionais, há perda total de capacidade para realização de trabalho e/ou problemas de saúde (Frota e Schiffer, 2001).

De acordo com Guo et al. (2014), as pessoas têm capacidade de se adaptar a climas locais específicos, no entanto, temperaturas extremas frias e quentes ainda estão associadas com um risco aumentado de mortalidade. A implantação de estratégias de saúde pública para aliviar o impacto das temperaturas ambientes são importantes, em particular no contexto das mudanças climáticas (Guirguis et al., 2018).

Para auxiliar à identificação de situações de conforto e de desconforto humano em relação ao ambiente no qual está inserido, foram desenvolvidos alguns índices biofísicos baseados em diferentes aspectos do conforto térmico humano, baseando-se nas trocas de calor entre o corpo e o ambiente. Já os índices fisiológicos se baseiam nas reações fisiológicas originadas por condições conhecidas de temperatura seca do ar, temperatura radiante média, umidade do ar e velocidade do vento e índices subjetivos, que tem como base as sensações subjetivas de conforto experimentadas em condições em que os elementos de conforto térmico variam (Silva et al., 2018).

Neste caso, estabelecer os parâmetros relativos às condições de conforto térmico requer incorporar, além das variáveis climáticas, as temperaturas das superfícies presentes no ambiente e a atividade desenvolvida pelas pessoas (Frota e Schiffer, 2001; Thorsson et al., 2016; Unger et al., 2017).

Logo, este trabalho teve como objetivo principal avaliar, quantitativamente, o ciclo diurno da situação de conforto e desconforto térmico em Maceió no período de 2004 a 2015, por meio da análise do índice de desconforto humano (IDK), proposto por Ono e Kawamura (1991), um dos índices mais utilizados em regiões tropicais, e analisar possíveis tendências temporais do IDK no período de estudo através do teste de Mann-Kendall.

\section{Materiais e Métodos}

\section{1. Área de estudo}

A área de realização desse estudo foi a cidade de Maceió, capital do Estado de Alagoas. Localizada na região Nordeste do Brasil (NEB), a cidade do estudo apresenta um clima tropical (quente e úmido), seu relevo é composto por planícies litorâneas, maciço cristalino e tabuleiros costeiros e apresenta uma vegetação do tipo arbustiva, herbácea, sendo característica do bioma Mata Atlântica. Correia-Filho et al. (2019) mostraram o impacto do uso e ocupação do solo no aumento de temperatura observado na cidade de Maceió, que já ultrapassa 1 milhão de habitantes (IBGE, 2018). 


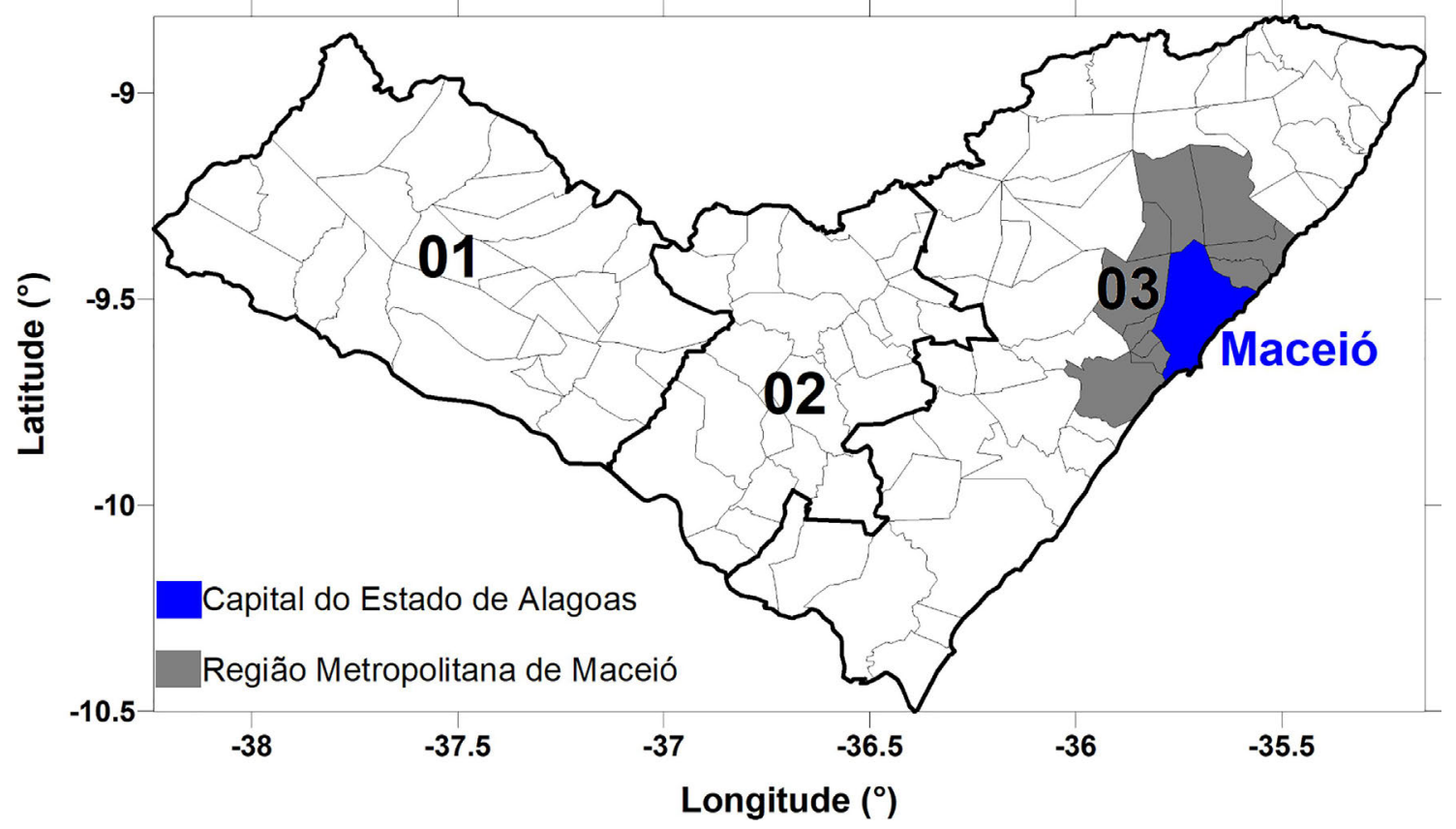

Figura 1 - Capital do Estado de Alagoas (azul) e sua região metropolitana (cinza).

\subsection{Dados}

Foram utilizados dados horários da estação meteorológica automática, localizada em Maceió para o período de 2004 a 2015. Essa estação é de responsabilidade do Instituto Nacional de Meteorologia (INMET), e está localizada, desde sua instalação em 25/02/2003, na Universidade Federal de Alagoas.

\subsection{CLIMAP: Aplicativo para análise de dados climáticos}

O CLIMAP é uma ferramenta computacional para análise de dados meteorológicos diários. As variáveis meteorológicas analisadas são três fixas: precipitação, temperatura máxima e temperatura mínima, e uma quarta variável escolhida pelo usuário. Para este trabalho foram utilizadas técnicas estatísticas para análise de variação e tendência, disponibilizadas por este aplicativo, para a elaboração dos gráficos com os dados de $\operatorname{ID}_{\mathrm{K}}$ (Salvador, 2017).

As tendências lineares do $\mathrm{ID}_{\mathrm{K}}$ foram obtidas por funções de regressão linear, que consiste na realização de uma análise estatística, com o objetivo de verificar a relação entre uma variável dependente com uma ou mais variáveis independentes, utilizando o método dos mínimos quadrados, cuja tendência é dada pelo coeficiente angular da reta $y=a x+b$, estimada em relação ao eixo $x$. Para testar a significância estatística da tendência linear, a fim de verificar se a mesma não é consequência exclusiva da aleatoriedade intrínseca da variável em estudo, utiliza-se o p-valor, sendo considerados como tendências significativas (positiva ou negativa) àquelas em que estas apresen- tarem uma reta derivada linear superior ao erro padrão da estimativa e p-valor $\leq 0,05$, ao nível de $95 \%$ de confiança (Salvador e Brito, 2018).

Não é confiável verificar e atestar a significância estatística de tendências apenas com a análise de regressão linear. Usar outra técnica, de preferência não paramétrica, é recomendável. Assim utilizou-se também o teste nãoparamétrico de Mann-Kendall (MK) para determinar a existência e significância das tendências observadas, como descrito em Costa et al. (2020).

$\mathrm{O}$ teste de MK consiste em calcular duas séries de valores estatísticos, uma a partir do início e outra a partir do final da série. Estas séries são mostradas sob a forma de duas curvas denominadas respectivamente de curva direta $U i$ e curva retrógrada $U^{\prime} i$. A tendência é significativa quando a curva $U(t)$ excede o limiar superior a $5 \%$ ou $[U i]>1,96$, suportada pela estimativa do $\mathrm{p}$-valor proveniente do teste $t$ de Student. O ponto que marca o início da mudança corresponde à intersecção entre as curvas direta $U i$ e retrógrada $U^{\prime} i$. Graficamente, as curvas retrógradas e diretas são frequentemente confusas quando não há uma tendência significativa na série. Quando os valores de $U(t)$ são significativos, conclui-se a uma tendência crescente ou decrescente, para $U(t)>0$ ou $U(t)<0$, respectivamente (Salvador e Brito, 2018; Costa et al., 2020).

Por fim analisa-se o coeficiente de correlação denominado de $\tau$ (tau) de kendall ou Kendall- $\tau$, uma medida de associação para variáveis ordinais. Sua principal vantagem sobre medidas comuns de correlação é a de não ser influenciado pela variância ou outliers. Este coeficiente é definido como (Eq. (1)): 


$$
\tau=\frac{n_{c}-n_{d}}{\frac{1}{2} n(n-1)}
$$

onde $n_{c}$ é o número de pares concordantes, $n_{d}$ o número de pares discordantes. $\tau$ representa a probabilidade de que dois pontos da distribuição conjunta dos pares sejam concordantes, variando de -1 a 1 similar ao coeficiente de correlação de Pearson $(r)$.

\section{4. Índice de conforto térmico}

O IDK (Ono e Kawamura, 1991) utiliza a relação entre a temperatura do ar $(T)$ e a temperatura do ponto de orvalho $\left(T_{d}\right)$. Os valores do $\mathrm{ID}_{\mathrm{K}}$ são uma resposta à temperatura e a umidade atmosférica, representada na formulação do $\mathrm{ID}_{\mathrm{K}}$ pela temperatura do ponto de orvalho, que é a temperatura até a qual o ar (ou gás) deve ser resfriado para que a condensação de água se inicie, ou seja, para que o ar fique saturado de vapor de água (Górnicki et al., 2017), sendo a quantidade de vapor d'água presente no ar máxima na temperatura do ponto de orvalho. A Eq. (2) a seguir mostra essa relação. Apesar de relacionar duas medidas de temperatura este índice é considerado adimensional na literatura.

$$
I D K=0,99 \times T+0,36 \times T_{d}+41,5
$$

em que $T$ é a temperatura do ar e $T_{d}$ é a temperatura do ponto de orvalho. Por meio dessa equação foi possível avaliar o índice de desconforto humano e realizar comparações conforme a Tabela 1 .
Tabela 1 - Índices de conforto térmico.

\begin{tabular}{lc}
\hline Valores do $\mathrm{ID}_{\mathrm{K}}$ & Sensação térmica \\
\hline $\mathrm{IDK}>80$ & Estresse devido ao calor \\
$75 \leq \mathrm{IDK}<80$ & Desconforto devido ao calor \\
$60 \leq \mathrm{IDK}<75$ & Confortável \\
$55 \leq \mathrm{IDK}<60$ & Desconforto devido ao frio \\
$\mathrm{IDK}<55$ & Estresse devido ao frio \\
\hline
\end{tabular}

\section{Resultados e Discussão}

\subsection{IDK médio no período}

A distribuição mensal do IDK é mostrada na Fig. 2, obtida a partir dos dados horários de $T$ e $T_{d}$ de todos os meses entre 2004 e 2015, em um gráfico do tipo violin plot. Este tipo de gráfico combina as vantagens dos gráficos tipo box-plot, com medianas e intervalos interquartis, e também mostra toda a distribuição dos dados por meio de funções densidade de kernel. Isso é de interesse, especialmente quando se lida com dados multimodais, isto é, uma distribuição com mais de um pico. De maio a novembro, predominam as condições de conforto térmico, com IDK variando em média de 72,3 em agosto, quando apresenta seus valores mais baixos, a 74,4 em maio e novembro. Importante destacar os valores médios mensais de dezembro a abril, superiores a 75, indicando que nestes meses predomina o desconforto pelo calor. O máximo médio mensal se dá em março, que marca o final do verão e início do outono, com IDK 76, na faixa do desconforto por calor.

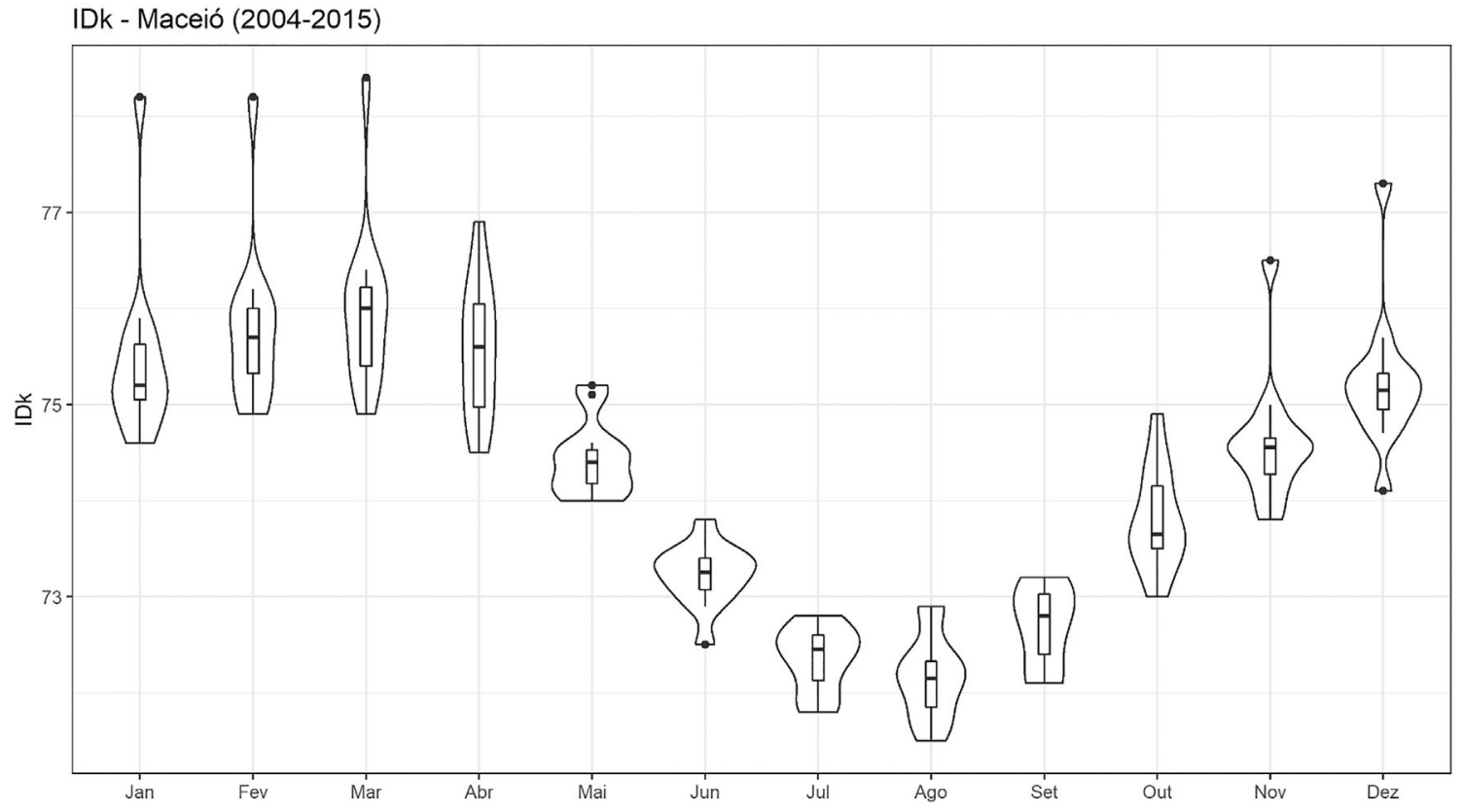

Figura 2 - Distribuições mensais do IDK em Maceió (AL), para o período 2004-2015, em gráfico violin plot. 
A Fig. 3 mostra a distribuição diária dos valores do IDK em Maceió no período estudado. O comportamento esperado do IDK com os maiores valores próximos do verão e menores durante o inverno é observado em todos os anos. No entanto, um comportamento anômalo no início da série foi observado entre o final de 2004 e o início do ano de 2005, quando o IDK supera abruptamente o limiar de 75, que dá início a faixa de desconforto pelo calor, e chega a ultrapassar o valor de 80 , de estresse pelo calor. Para que um valor médio diário do IDK esteja inserido na faixa de desconforto pelo calor, ou mesmo de estresse pelo calor, significa inferir que nestes dias, na maioria das horas, predominou as sensações de desconforto e stress.

O resultado da Fig. 3 motivou uma avaliação horária da contagem de número de horas com estresse pelo calor, desconforto pelo calor e condição de conforto. Tais resultados são mostrados na Fig. 4 (número de horas com estresse pelo calor), Fig. 5 (número de horas com desconforto pelo calor) e Fig. 6 (número de horas com conforto térmico).

A Fig. 4 mostra a contagem de horas com valores de IDK superiores a 80 , ou seja, com estresse pelo calor. Percebe-se, excluindo-se o período atípico entre 2004 e 2005, que o número de horas com estresse pelo calor em Maceió situa-se entre 50 a 70 horas por ano, principalmente no período do verão. Dois períodos atípicos são observados na Figura 4, o excessivo número de horas com estresse pelo calor observado entre 2004 e 2005. Em julho de 2004, um dos meses juntamente com junho e agosto com valores mais baixos de IDK, foram registradas 6 horas com estresse por calor. De agosto de 2004 a maio de 2005 , foram registrados 1866 horas com estresse pelo calor. O máximo de horas com estresse foi registrado em janeiro de 2005, com 304 horas de estresse por calor. Este é um forte indício de uma intensa onda de calor que ocorreu em Maceió, por sete meses, entre outubro de 2004 e abril de 2005.

A Fig. 5 mostra a contagem de horas com valores de IDK 75 e 80, ou seja, em condições de desconforto pelo calor. Nota-se que, ao contrário da Fig. 5, o sinal de estresse pelo calor não permanece na contagem de horas com desconforto. Este resultado permite inferir que durante esta forte onda de calor, e os dados permitiram identificar isto, as condições diárias de conforto ambiental durante uma onda de calor em Maceió passam bruscamente da condição de conforto térmico para estresse pelo calor, com menos horas de desconforto pelo calor quando compara-se anos normais. Pode-se dizer que durante a onda de calor, o estresse pelo calor rapidamente alcançado no ambiente diminui o número de horas com desconforto, expondo a população a um número elevado no dia de horas com extremos de calor, o que pode trazer inúmeras consequências a saúde humana.

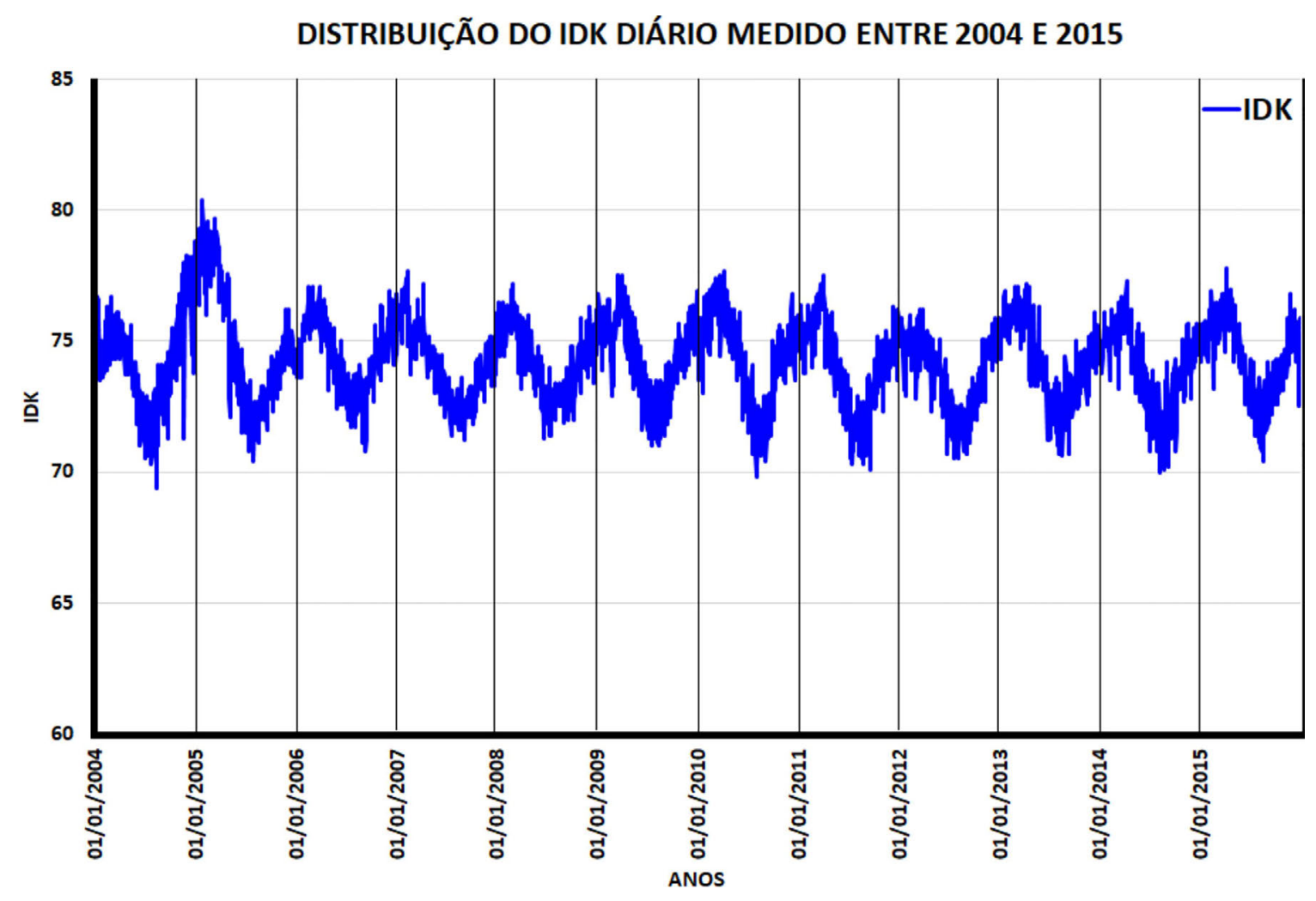

Figura 3 - Valores diários do IDK calculados entre 2004 e 2015 para Maceió (AL). 


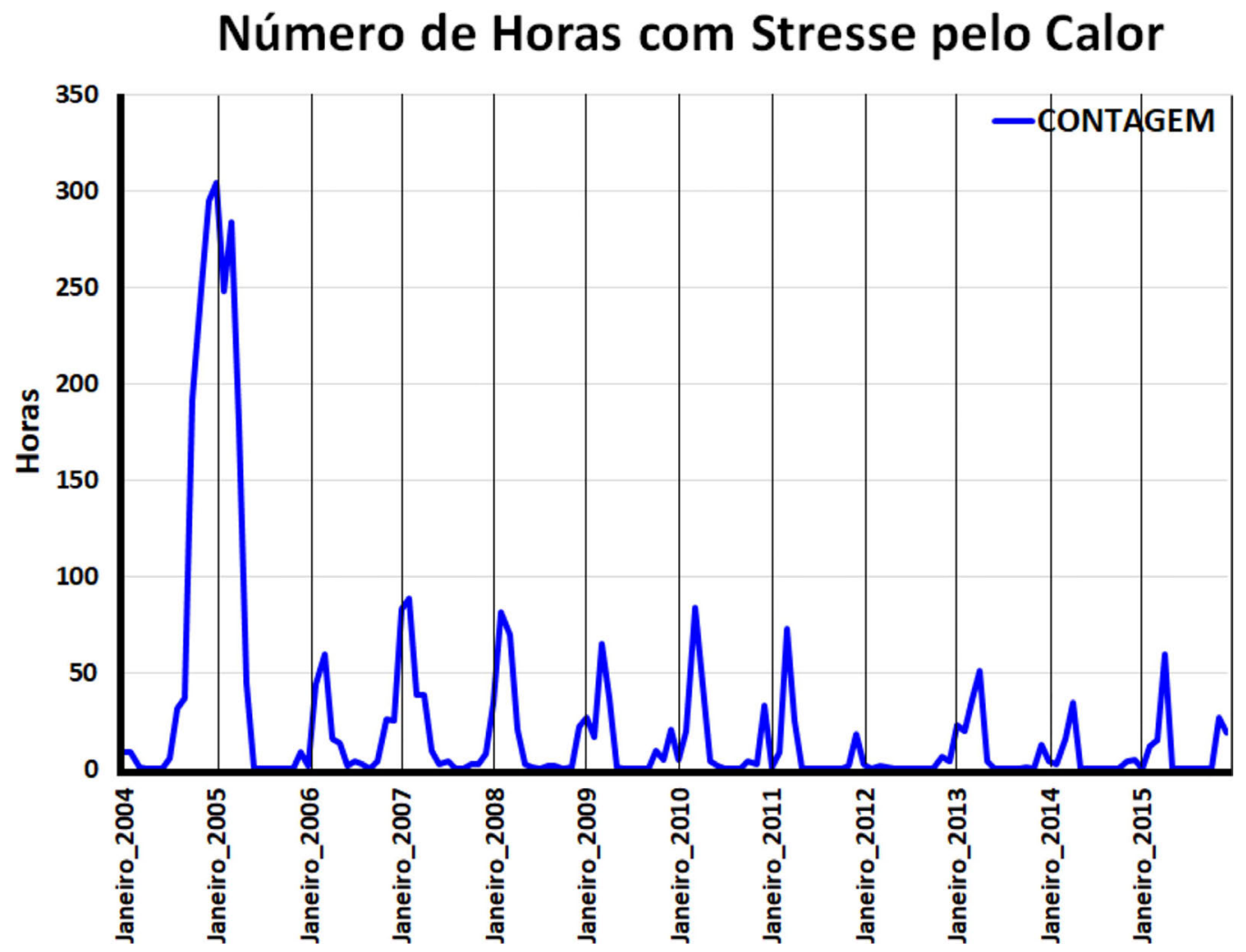

Figura 4 - Número de horas contabilizadas com estresse pelo calor de janeiro de 2004 a dezembro de 2015.

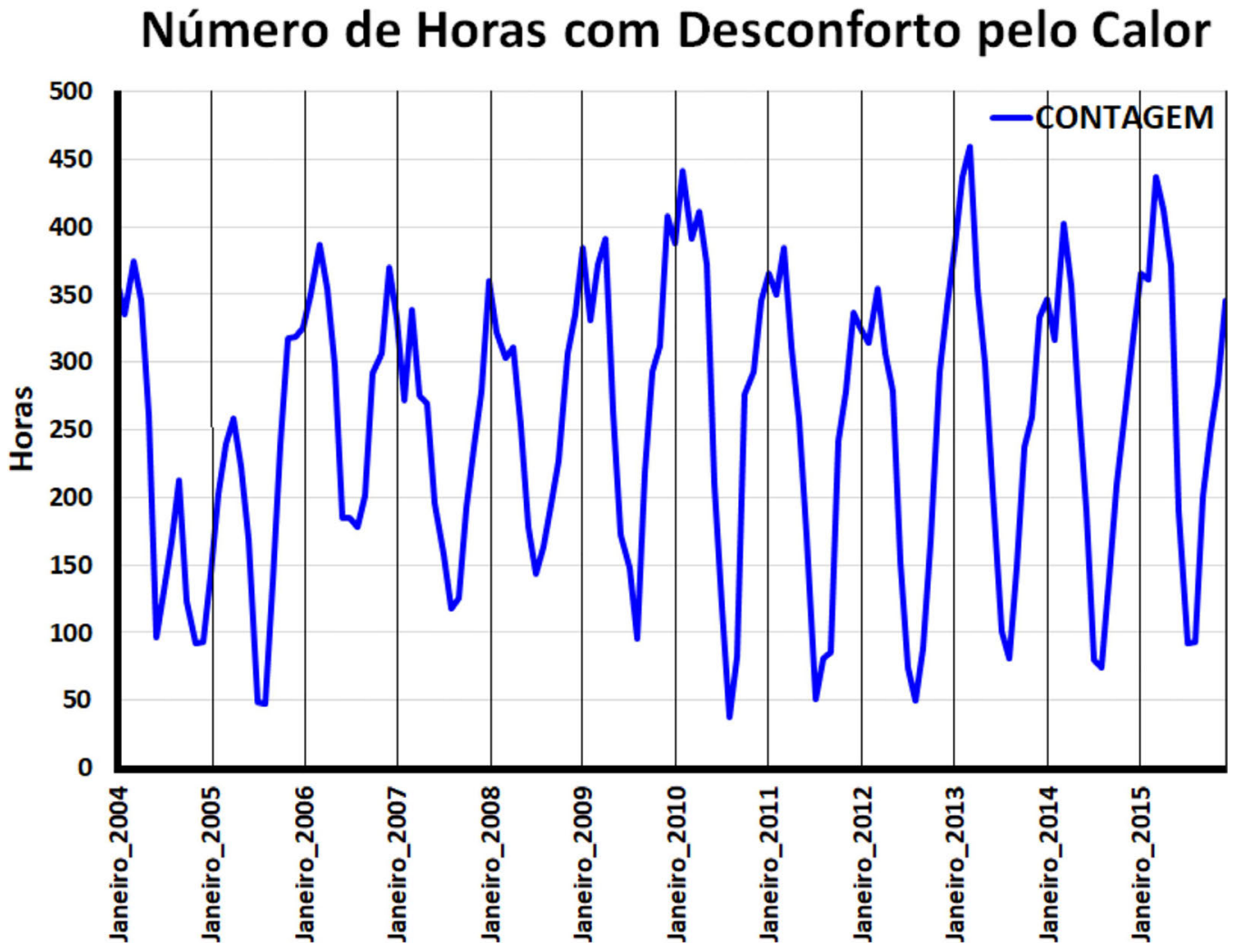

Figura 5 - Número de horas contabilizadas de IDK de 75 a 80 com desconforto pelo calor de janeiro de 2004 a dezembro de 2015. 
Percebe-se que a partir de 2013 a 2015, há uma elevação no número de horas com desconforto se comparamos com o período de 2006 a 2009. Isto pode estar associado a recente condição de seca experimentada em todo o Nordeste do Brasil desde 2012 (Cunha et al., 2015; Marengo et al., 2018).

A Fig. 6 mostra a variação do número de horas com conforto térmico. Percebe-se a sazonalidade já mostrada nas médias do IDK, com maior número de horas com conforto nos meses de junho a agosto, e menor número de horas de conforto entre outubro e março. Os três picos de menor número de horas com conforto foram observados no verão 2004/2005, associado à forte onda de calor discutida, e nos verões de 2009/2010 e 2012/2013, podendo ser associadas aos verões secos ocorridos nestes anos ( $\mathrm{Cu}-$ nha et al., 2018; Martins et al., 2018).

\subsection{Histogramas}

Diante do exposto no item 3.1, surgiu a necessidade de estudar a variabilidade das condições de conforto térmico hora a hora. A primeira forma de análise foi por meio de histogramas horários (Fig. 7), obtidos a partir de todos os valores de cada hora entre os anos estudados.

Das 02 UTC às 08 UTC, predomina a condição de conforto, com predomínio da classe de valores de IDK entre 70 e 75. A classe de valores de IDK entre 65 e 70, mais distante da classe do desconforto pelo calor, aumenta gradualmente entre às 05 UTC e às 08 UTC.

A partir das 09 UTC, há um leve aumento nos valores da classe do desconforto pelo calor, entre 75 a 80 . No entanto, os valores que apontam situação confortável são superiores aos que indicam sensação térmica de desconforto por calor. As 10 UTC, os valores de IDK entre 75 a 80 , sofrem um aumento considerável em relação as 09 UTC. Um outro índice que passa a ter um leve aumento está representado na faixa entre 80 a 85 , o que já indica que há situação de estresse devido ao calor. No entanto, os maiores valores de IDK ainda são relativos a classe de conforto térmico.

A partir das 11 UTC, a classe de desconforto pelo calor passa ser mais frequente até as 20 UTC. Das 11 UTC as 19 UTC, a classe de estresse pelo calor está sempre presente, com maior frequência das 14 UTC as 17 UTC. Esta classe volta a desaparecer as 20 UTC, quando as ocorrências de desconforto pelo calor superam as de conforto.

A partir das 21 UTC, os casos referentes a classe de desconforto pelo calor regridem progressivamente até as 23 UTC, quando é superada pela classe referente ao conforto térmico.

Estes resultados devem ser observados com precaução. Fica claro o quanto a população de Maceió é exposta, a depender da época do ano, assim como do horário

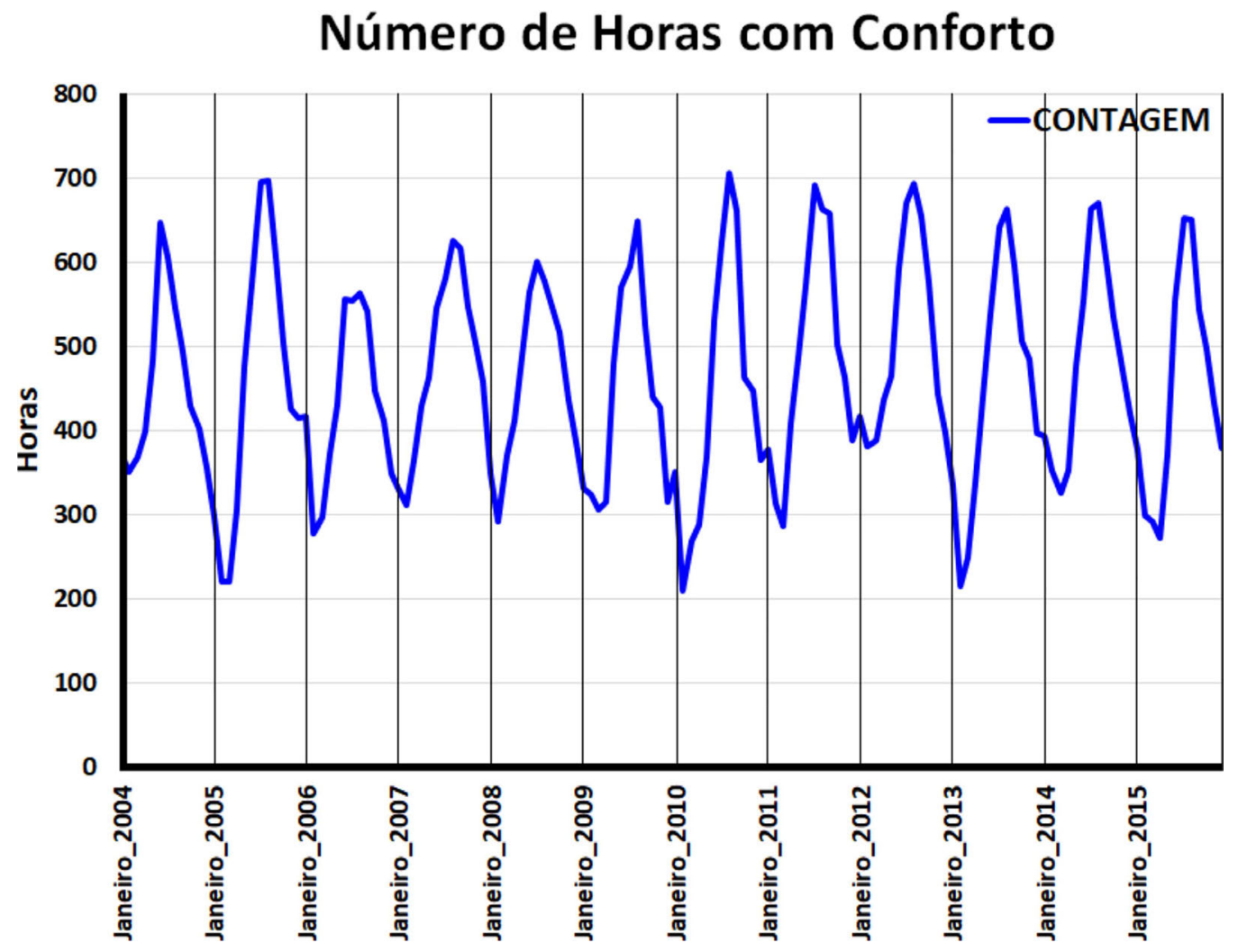

Figura 6 - Número de horas contabilizadas com conforto térmico de janeiro de 2004 a dezembro de 2015. 
do dia, a situações de desconforto pelo calor e também, de estresse pelo calor.

\subsection{Gráficos box-plot}

A Fig. 8 mostra a distribuição dos valores horários de IDK por meio dos gráficos de box-plot. O uso desse tipo de gráfico é importante por possibilitar a verificação de outliers, valores que se distanciam muito da maioria dos seus dados, que podem ser gerados por erros de mensuração ou por ocorrência valores extremos.

Os gráficos das 00 UTC às 02 UTC são muito similares, o que mostra a baixa variabilidade do IDK entre estes horários. Em seguida, com o declínio da temperatura e seu reflexo na diminuição do IDK, nota-se a similaridade
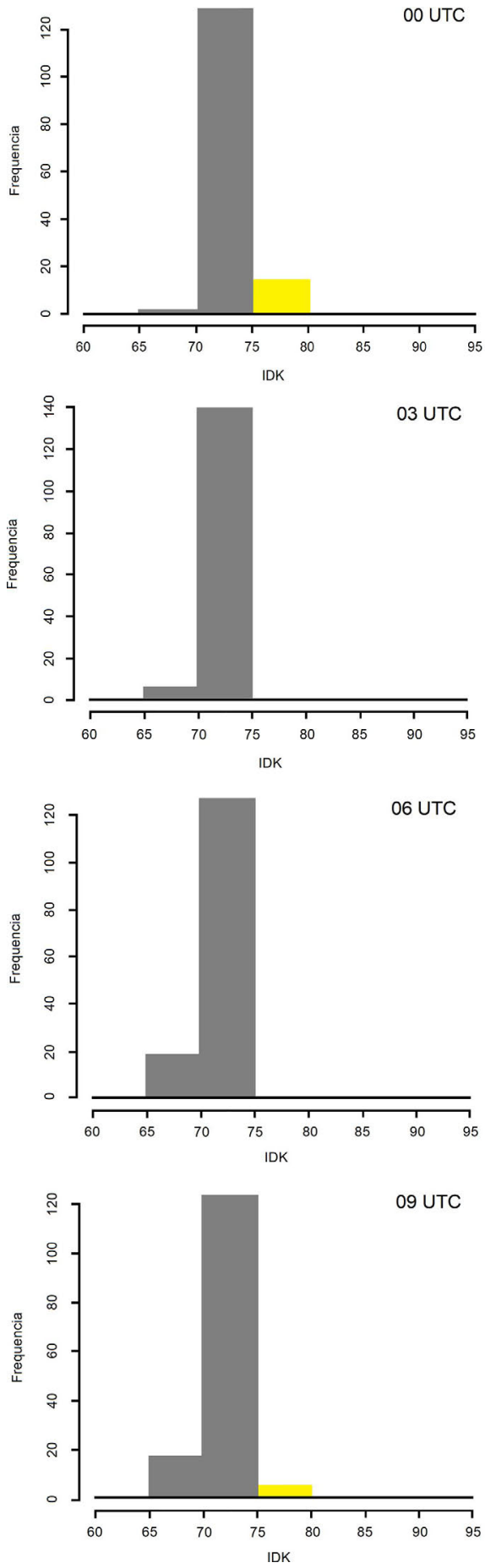
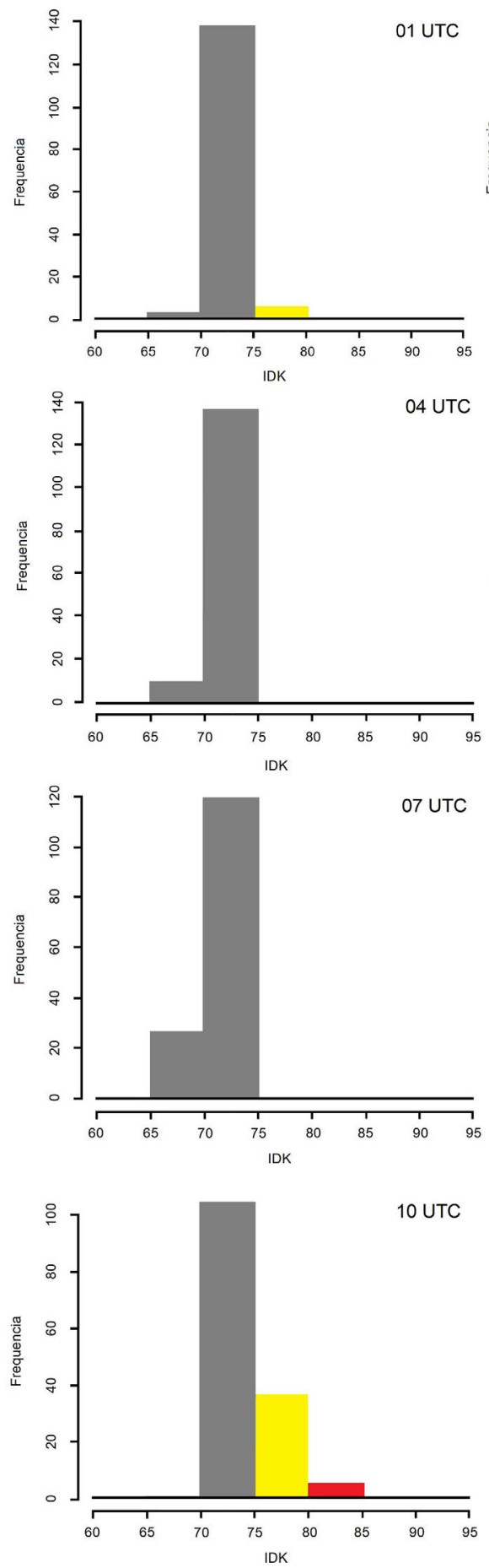
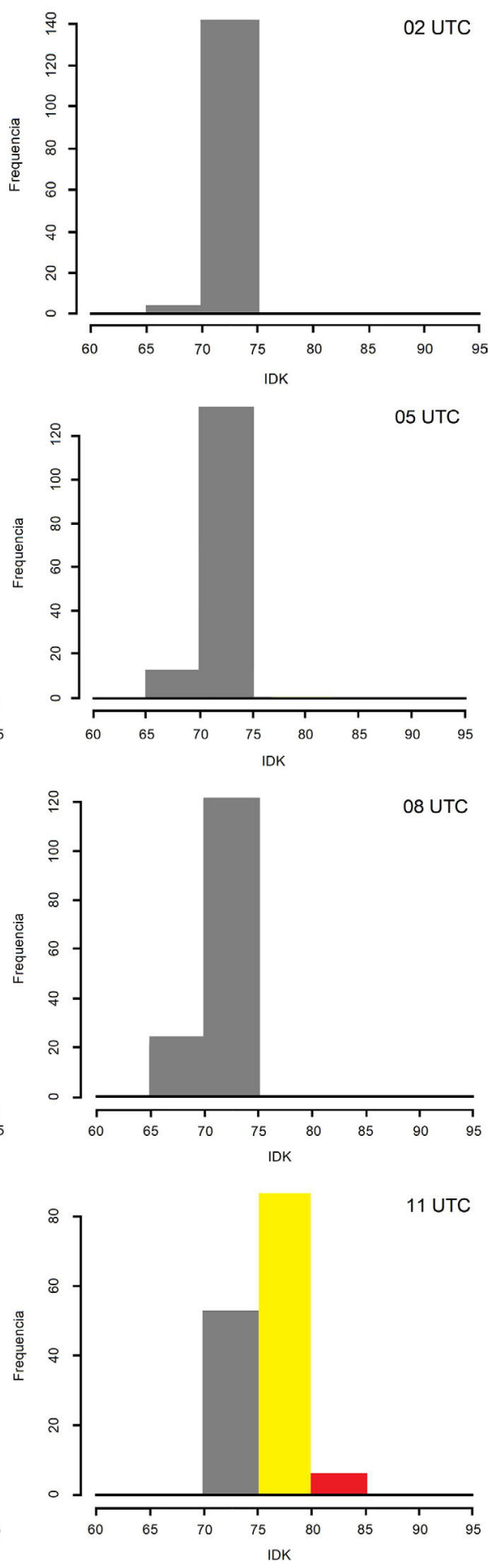

Figura 7 - Histogramas de frequência das classes relativas ao conforto térmico (destacas em cinza), ao desconforto pelo calor (destacadas em amarelo), e ao estresse pelo calor (em vermelho). A sequência está organizada em blocos de quatro figuras, desde às 00 UTC até às 23 UTC. 

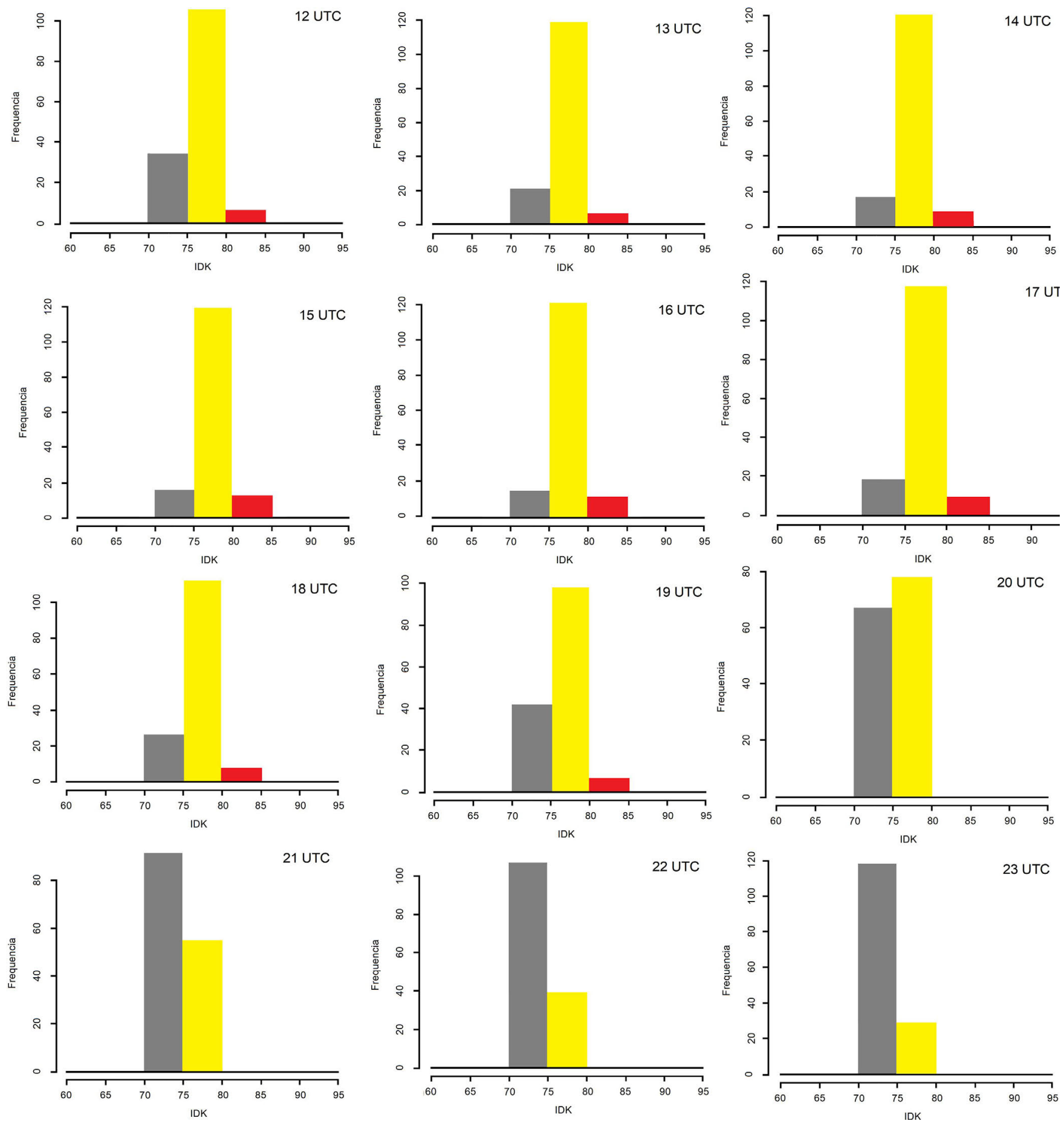

Figura 7 (cont.) - Histogramas de frequência das classes relativas ao conforto térmico (destacas em cinza), ao desconforto pelo calor (destacadas em amarelo), e ao estresse pelo calor (em vermelho). A sequência está organizada em blocos de quatro figuras, desde às 00 UTC até às 23 UTC.

dos gráficos das 03 UTC as 06 UTC. A partir das 09 UTC, com a elevação da temperatura e dos valores do IDK, ressalta-se o que foi anteriormente discutido, que a brusca passagem de valores de IDK que indicam conforto para valores de IDK que indicam desconforto e estresse por calor, faz com que tais ocorrências sejam interpretadas como outliers nos box-plots das 09 UTC até às 19 UTC.

\subsection{Tendência linear e teste de Mann Kendall (MK)}

Os gráficos da Fig. 9 mostram as respectivas retas de tendência linear para cada mês do ano (gráficos superiores), com o respectivo teste sequencial de $\mathrm{MK}$ a fim de validar as tendências obtidas do IDK via regressão linear (gráficos inferiores). 

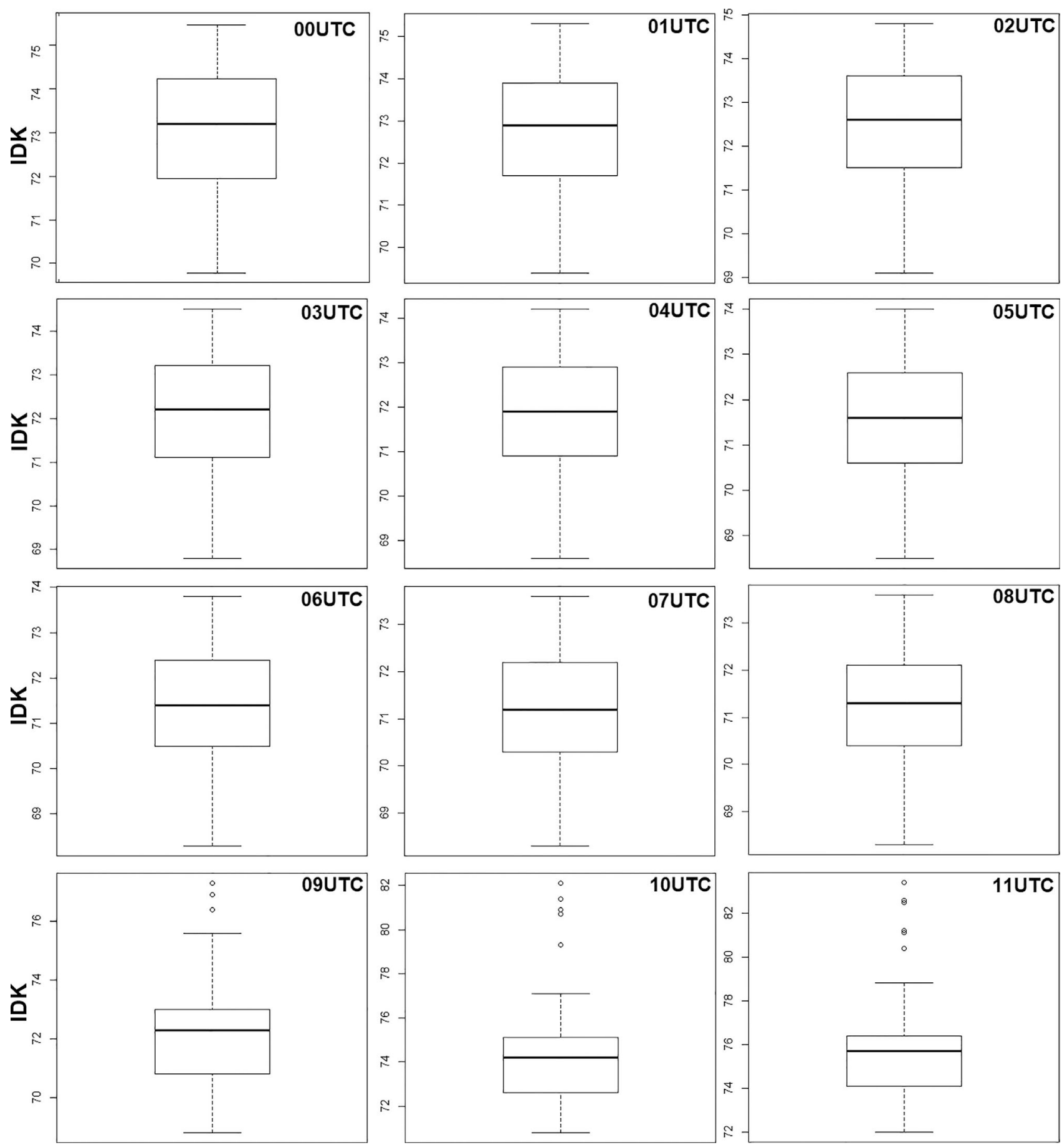

Figura 8 - Gráficos Box-Plot em sequência, organizados em blocos de três figuras, desde às 00 UTC até ás 23 UTC.

Entre janeiro e março, há tendências negativas de IDK sem significância estatística, como efeito da forte onda de calor observada no início da série, entre a primavera de 2004, verão de 2004/2005 e início do outono de 2005. Entre abril a junho a situação é inversa, com tendências positivas não significativas. De julho a dezembro as tendências voltam a ser negativas, com significância estatística a um nível de confiança de $90 \%$ apenas no mês de agosto, com p-valor igual a 0,074 e coeficiente de correlação $r=-0,53$.

Nos meses de janeiro e fevereiro, as curvas direta Ui e retrógrada $U^{\prime} i$ se cruzam dentro dos limites de confiança, com o provável ponto de mudança em 2012. No mês de agosto, esta característica volta a ocorrer aproximadamente no ano de 2007, mas ainda dentro dos limites. Quando estas retas se cruzam fora dos limites de confiança, fica 

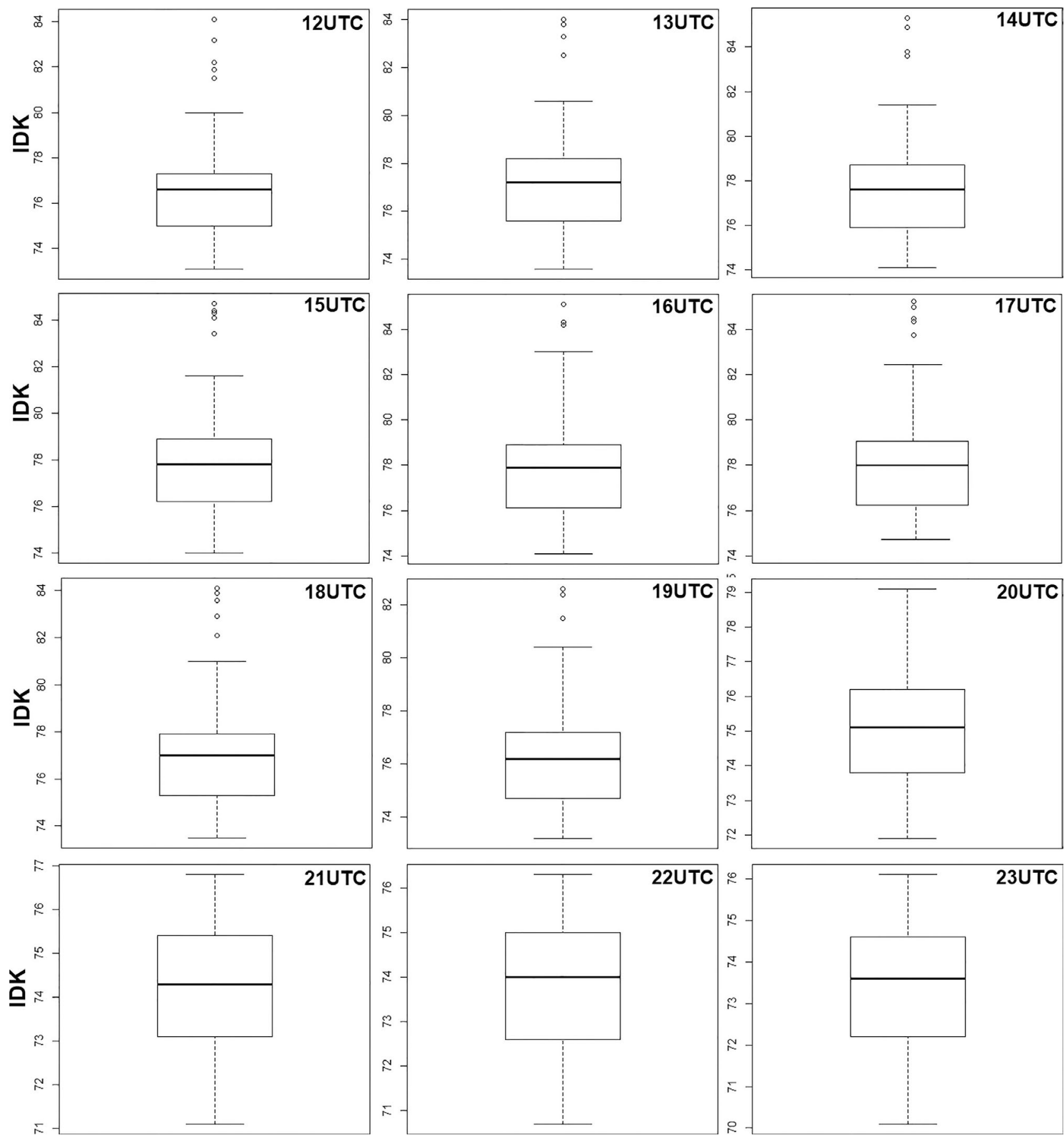

Figura 8 (cont.) - Gráficos Box-Plot em sequência, organizados em blocos de três figuras, desde às 00 UTC até ás 23 UTC.

evidenciado um provável ponto de início para uma mudança de patamar, ou de comportamento da tendência observada. Quando este cruzamento se dá dentro das linhas dos limites de confiança, não se pode afirmar com certeza que o ano relativo ao cruzamento indica um real ponto de inflexão.

\section{Conclusões}

A partir dos resultados obtidos por meio dos gráficos e dos dados analisados para o período de 2004 a 2015, foi possível perceber que os valores de IDK sofrem alterações ao longo dos anos. As sensações térmicas diárias variam 

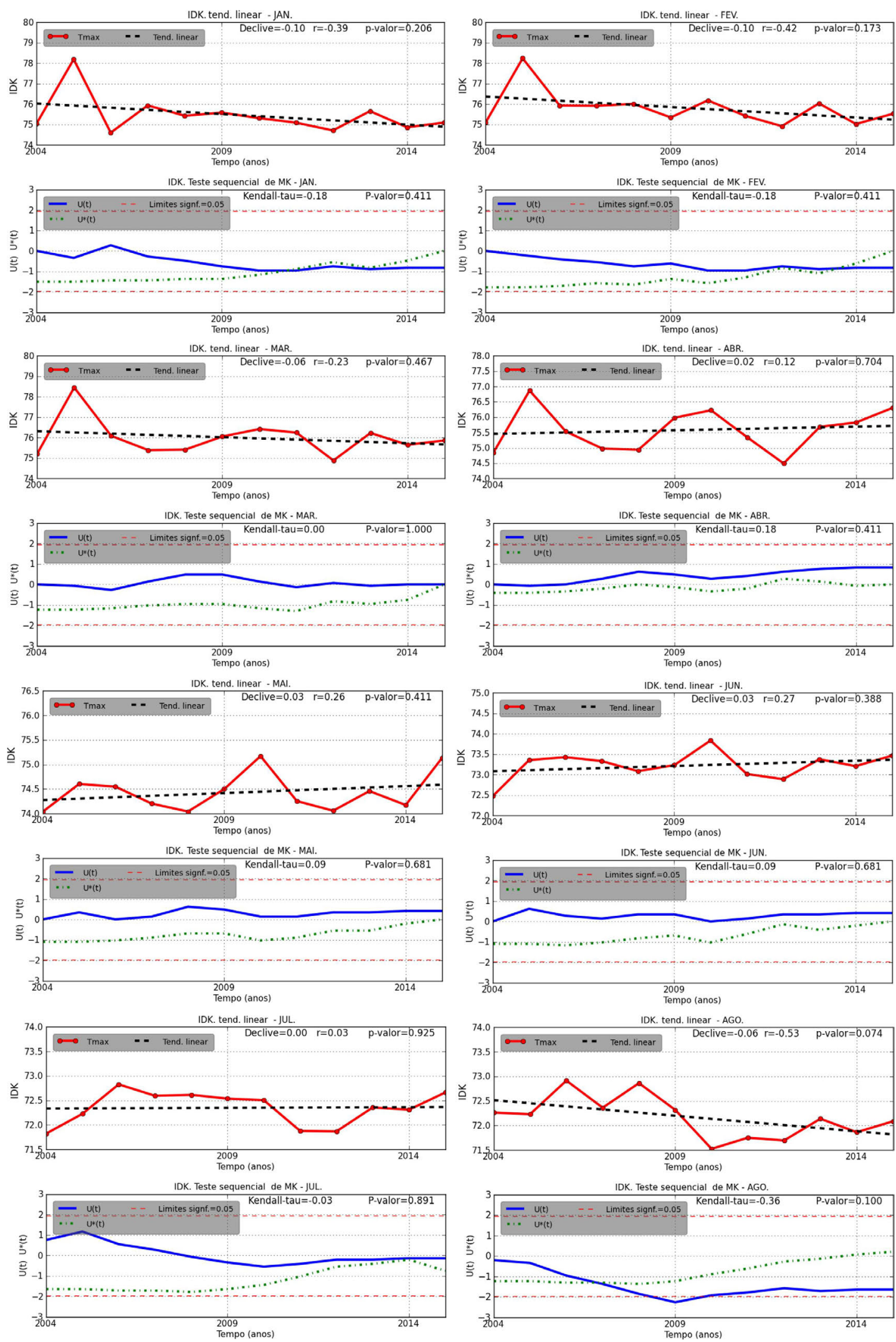

Figura 9 - Nos gráficos superiores, linha de tendência e parâmetros estatísticos da reta em relação ao tempo (declive, $r$ e p-valor para a significância estatística da inclinação da reta). Nos gráficos inferiores, teste sequencial de MK para a média mensal dos valores de IDK para cada mês do ano, na sequência de janeiro a dezembro, no período 2004-2015. 

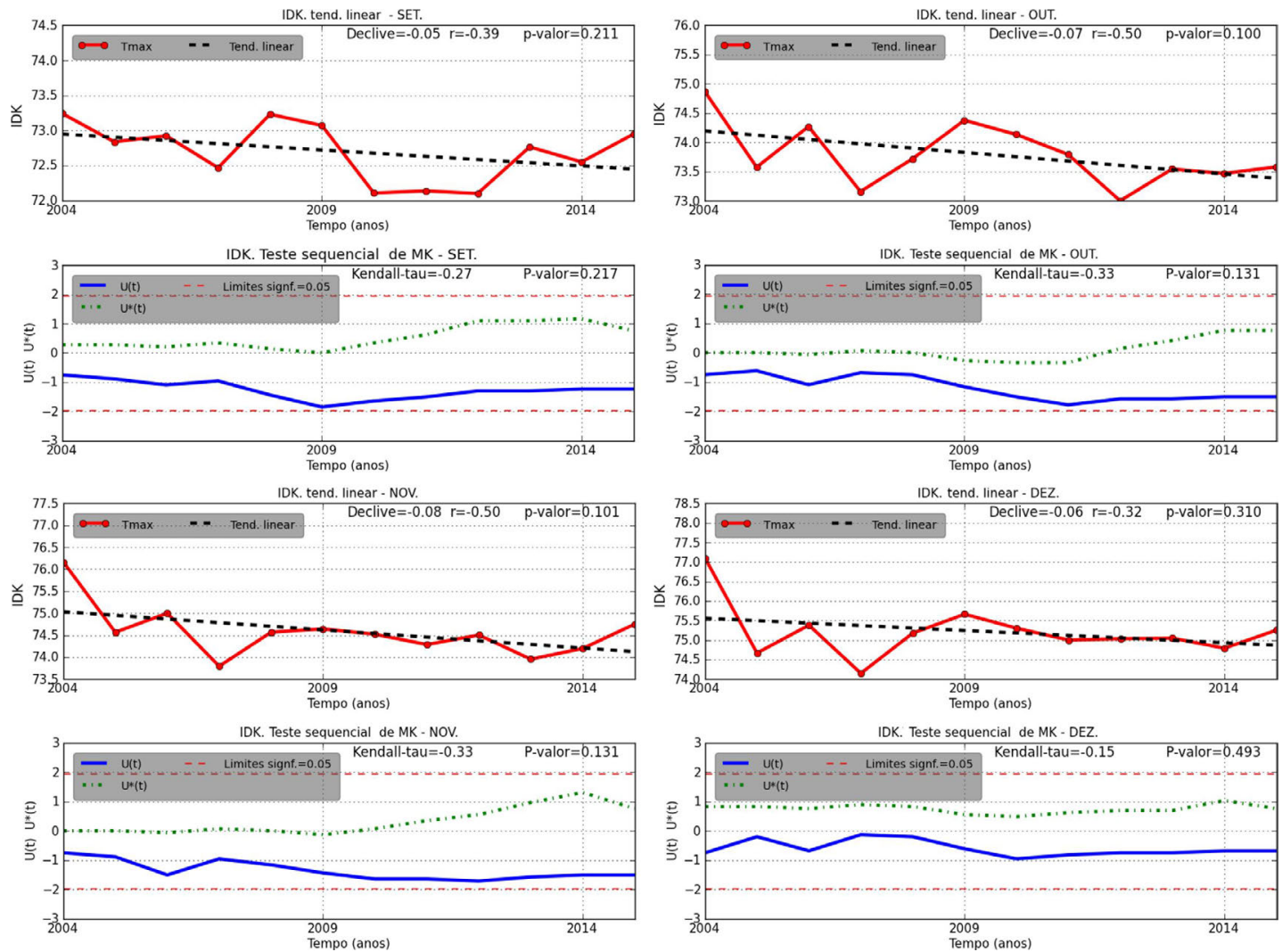

Figura 9 (cont.) - Nos gráficos superiores, linha de tendência e parâmetros estatísticos da reta em relação ao tempo (declive, $r$ e p-valor para a significância estatística da inclinação da reta). Nos gráficos inferiores, teste sequencial de MK para a média mensal dos valores de IDK para cada mês do ano, na sequência de janeiro a dezembro, no período 2004-2015.

de conforto a desconforto e estresse pelo calor a depender da época do ano.

Durante a variação das horas do dia, de 00 a 23 UTC, foi observado que em média, de 00 às 09 horas UTC a sensação de conforto térmico prevalece, as vezes com um leve aumento de desconforto. Já das 11 às 20 UTC chega a prevalecer a sensação de desconforto térmico. A partir das 21 UTC o desconforto devido ao calor vai apresentando uma diminuição e o conforto começa a aumentar, prevalecendo essa sensação.

Não foram encontrados casos de desconfortos ou estresses devido ao frio, pelo fato da cidade de Maceió localizar-se em região tropicas quase ao nível médio do mar.

Os resultados mostraram a atuação de uma forte onda de calor no início da série de dados, entre a primavera de 2004 e o outono de 2005, com os recordes de horas com estresse pelo calor ocorrendo nestes meses destes anos.

Sugere-se como trabalhos futuros pesquisas que identifiquem os sistemas meteorológicos que levam a tais condições de prevalência de condições de conforto, desconforto e estresse pelo calor na cidade de Maceió.

\section{Agradecimentos}

Os autores agradecem a Coordenação de Aperfeiçoamento de Pessoal de Nível Superior (CAPES) pelo apoio financeiro concedido durante a concepção deste estudo, e para a sua publicação.

\section{Referências}

AZEVEDO, P.V.; BEZERRA, P.T.C.; LEITÃO, M.M.V.B.; SANTOS, C.A.C. Characterization of human thermal comfort in urban areas of brazilian semiarid. Revista Brasileira de Meteorologia, v. 30, n. 4, p. 371 - 380, 2015.

BRACARENSE, L.S.F.P.; CRUZ, B.C.B.L.; MONTEIRO, A.J.F; SANTOS, A.P.F.; VENÂNCIO, S.L.A.; PEREIRA, E.C. Índices de Conforto Térmico: Limitações e Variações de Classificação. In: Congresso Luso-Brasileiro para o Planejamento Urbano, Regional, Integrado e Sustentável, 8, Coimbra, Anais, 2018.

CORREIA-FILHO, W.L.F.; SANTIAGO, D.B.; OLIVEIRA JÚNIOR, J.F.; SILVA-JÚNIOR, C.A. Impact of urban decadal advance on land use and land cover and surface temperature in the city of Maceió, Brazil. Land Use Policy, v. 87, 104026, 2019. 
COSTA, R.L.; BAPTISTA, G.M.M.; GOMES, H.B.; SILVA, F.D.S.; ROCHA-JÚNIOR, R.L.; SALVADOR, M.A.; HERDIES, D.L. Analysis of climate extremes indices over northeast Brazil from 1961 to 2014. Weather and Climate Extremes, v. 28, 100254, 2020.

CUNHA, A.P.M.A.; ALVALÁ, R.C.S.; NOBRE, C.A.; CARVALHO, M.A. Monitoring vegetative drought dynamics in the Brazilian semiarid Region. Agricultural and Forest Meteorology, v. 214-215, p. 494-505, 2015.

CUNHA, A.P.M.A., TOMASELLA, J., RIBEIRO-NETO, G.G., BROWN, M., GARCIA, S.R., BRITO, S.B., CARVALHO, M.A. Changes in the spatial-temporal patterns of droughts in the Brazilian Northeast. Atmospheric Science Letters, v. 19, n. 10, e855, 2018.

FREITAS, E.D.; ROZOFF, C.M.; COTTON, W.R.; DIAS, P.L.S. Interactions of an urban heat island and sea-breeze circulations during winter over the metropolitan area of São Paulo, Brazil. Boundary-Layer Meteorology, v. 122, n. 1, p. 4365, 2007.

FROTA, A.B; SCHIFFER, S.R. Manual de Conforto Térmico. 5. ed. São Paulo: Editora Studio Nobel, 2001.

GORNICKI, K.; WINICZENKO, R.; KALETA, A.; CHOINSKA, A. Evaluation of models for the dew point temperature determination. Technical Sciences, v. 20, n. 3, p. 241-257, 2017.

GUIRGUIS, K.; GERSHUNOV, A.; CAYAN, D.R.; PIERCE, D.W. Heat wave probability in the changing climate of the Southwest US. Climate Dynamics, v. 50, n, 9-10, p. 38533864, 2018.

GUO, Y.; GASPARRINI, A.; ARMSTRONG, B.; LI, S.; TAWATSUPA, B.; TOBIAS, A.; LAVIGNE, E.; COELHO, M.S.Z.S.; LEONE, M.; PAN, X.; TONG, S.; TIAN, L.; KIM, H.; HASHIZUME, M.; HONDA, Y.; GUO, Y-L.L.; WU, C-F.; PUNNASIRI, K.; YI, S-M.; MICHELOZZI, P.; SALDIVA, P.H.N.; WILLIAMS, G. Global Variation in the Effects of Ambient Temperature on Mortality - A Systematic Evaluation. Epidemiology, v. 25, n. 6, p. 781-789, 2014.

IBGE - Instituto Brasileiro de Geografia e Estatística, 2018. Produto Interno Bruto da cidade de Maceió. https://cidades. ibge.gov.br/brasil/al/maceio/panorama. (Acessado em 25 de Junho de 2020).

LABAKI, L.C; FONTES, M.S.G.C; BARTHOLOMEI, C.L.B; DACANAL, C. Conforto Térmico em Espaços Públicos de Passagem: Estudos em Ruas de Pedestres no Estado de São Paulo. Ambiente Construído, v. 12, n. 1, p. 167-183, 2012.

LI, H.; WEI, Y.D.; ZHOU, T. Spatiotemporal analysis of land development in transitional China. Habitat International, v. 67, p. 79-95, 2017.

MARENGO, J.A.; ALVES, L.M.; ALVALA, R.C.C.; CUNHA, A.P.M.A.; BRITO, S.B.; MORAES, O.L.L. Climatic characteristics of the 2010-2016 drought in the semiarid Northeast Brazil region. Anais da Academia Brasileira de Ciências, v. 90, n. 2(1), p. 1973-1985, 2018.

MARTINS, E.S.P.R.; COELHO, C.A.S.; HAARSMA, R.; OTTO, F.E.L.; KING, A.D.; VAN OLDENBORGH, G.J.;
KEW, S.; PHILIP, S.; JÚNIOR, F.C.V.; CULLEN, H. A multimethod attribution analysis of the prolonged northeast Brazil hydrometeorological drought (2012-16). Bulletin of the American Meteorological Society, v. 99, n. 1, p. 6569, 2018.

MOORE, M.; GOULD, P.; KEARY, B.S. Global urbanization and impact on health. International Journal of Hygiene and Environmental Health, v. 206, n. 4-5, p. 269-278, 2003.

ONO, H.S.P.; KAWAMURA T. Sensible climates in monsoon Asia. International Journal of Biometeorology, v. 35, n. 1, p. 39-47, 1991.

QAID, A.; LAMIT, H.B.; OSSEN, D.R.; SHAHMINAN, R.N.R. Urban heat island and thermal comfort conditions at microclimate scale in a tropical planned city. Energy and Buildings, v. 133, p. 577-595, 2016.

SALVADOR, M.A. CLIMAP-Aplicativo para análise de dados climáticos-versão 3.0. Revista Brasileira de Climatologia, v. 20, p. 349-374, 2017.

SALVADOR, M.A.; BRITO, J.I.B. Trend of annual temperature and frequency of extreme events in the MATOPIBA region of Brazil. Theoretical and Applied Climatology, v. 133, n. 6, p. 253-261, 2018.

SILVA, F.D.S.; COSTA, R.L.; ANTONIO, M.A.V.; AFONSO, E.O.; SANTOS, D.M.; MATEUS, N.P.A.; ANTONIO, J.F. Tendências observadas da evapotranspiração potencial no estado de Alagoas (1961-2016). Revista Brasileira de Geografia Física, v. 11, n. 1, p. 2036-2049, 2018.

THORSSON, S.; RAYNER, D.; LINDBERG, F.; MONTEIRO, A.; KATZSCHNER, L.; LAU, K. K-L.; CAMPE, S.; KATZSCHNER, A.; KONARSKA, J.; ONOMURA, S.; VELHO, S.; HOLMER, B. Present and projected future mean radiant temperature for three European cities. International Journal of Biometeorology, v. 61, n. 9, p. 15311543, 2017.

UNGER, J.; SKARBIT, N.; GAL, T. Evaluation of outdoor human thermal sensation of local climate zones based on long-term database. International Journal of Biometeorology, v. 62, n. 3, p. 183-193, 2017.

WANG, H.; HE, Q.; LIU, X.; ZHUANG, Y.; HONG, S. Global urbanization research from 1991 to 2009: A systematic research review. Landscape and Urban Planning, v. 104, n. 3-4, p. 299-309, 2012.

ZHAO, Q.; COELHO, M.S.Z.S.; LIA, S.; SALDIVA, P.H.N.; HUD, K.; ABRAMSONA, M.J.; HUXLEYE, R.R.; GUOA, Y. Spatiotemporal and demographic variation in the association between temperature variability and hospitalizations in Brazil during 2000-2015: A nationwide timeseries study. Environment International, v. 120, p. 345353,2018 .

License information: This is an open-access article distributed under the terms of the Creative Commons Attribution License (type CC-BY), which permits unrestricted use, distribution and reproduction in any medium, provided the original article is properly cited. 